\title{
A comprehensive review on indoor air quality monitoring systems for enhanced public health
}

\author{
Jagriti Saini ${ }^{* *}$, Maitreyee Dutta ${ }^{1}$ and Gonçalo Marques $^{2}$ (D)
}

\begin{abstract}
Indoor air pollution (IAP) is a relevant area of concern for most developing countries as it has a direct impact on mortality and morbidity. Around 3 billion people throughout the world use coal and biomass (crop residues, wood, dung, and charcoal) as the primary source of domestic energy. Moreover, humans spend $80-90 \%$ of their routine time indoors, so indoor air quality (IAQ) leaves a direct impact on overall health and work efficiency. In this paper, the authors described the relationship between IAP exposure and associated risks. The main idea is to discuss the use of wireless technologies for the development of cyber-physical systems for real-time monitoring. Furthermore, it provides a critical review of microcontrollers used for system designing and challenges in the development of real-time monitoring systems. This paper also presents some new ideas and scopes in the field of IAQ monitoring for the researchers.
\end{abstract}

Keywords: Developing countries, Environmental health, Indoor air quality monitoring, Indoor air pollution, Public health, Occupational health

\section{Introduction}

With the ongoing improvements in quality of life, breathing environment has become an essential area of concern for researchers in the twenty-first century. Many studies confirm that indoor air is more deadly then outdoor air [1]. Nowadays, $90 \%$ of the rural households in the most developing countries and around $50 \%$ of the world's population make use of unprocessed biomass for open fires and poorly functioning cooking stoves indoors. These deficient methods of cooking are responsible for indoor air pollution (IAP) and poor health of women as well as young children who are often exposed to such a polluted environment [2]. Biomass and coal smoke carry a wide range of harmful pollutants such as Particulate Matter (PM), Nitrogen Dioxide $\left(\mathrm{NO}_{2}\right)$, Carbon Monoxide (CO), Sulphur Oxides, polycyclic organic matter and formaldehyde $[3,4]$. Constant exposure to IAP due to the combustion of solid fuels is the common cause of several harmful diseases in developing countries. The list includes chronic

\footnotetext{
* Correspondence: jagritis1327@gmail.com

${ }^{1}$ National Institute of Technical Teachers' Training \& Research, Chandigarh 160019, India

Full list of author information is available at the end of the article
}

obstructive pulmonary disease (COPD), otitis media, acute respiratory infections, tuberculosis, asthma, lung cancer, cancer of larynx and nasopharynx, low birth rate, perinatal conditions and severe eye diseases that can even cause blindness $[5,6]$.

In the developed countries, the impact of modernization has brought a significant shift in indoor fire and heating systems from biomass fuels such as petroleum products and wood to electricity-based appliances. As per World Energy Outlook 2017 [7], even after several improvements in cooking measures, 1.3 billion people in developing Asia are expected to rely on biomass for cooking by the year 2030. As per current estimates, 2.8 million premature deaths are reported every year due to the use of coal and solid biomass for cooking [7]. The scenario becomes worse with the use of kerosene, candles and other harmful fuels for lighting [7]. Generally, the types of fuels being used for household needs can become cleaner and efficient only if people start moving up on the energy ladder. Note that, animal dung is the lowest level of this ladder, and the successive steps are built with crop residues, wood, charcoal, kerosene, gas, and electricity [8]. People throughout the world tend to move upward on this ladder 
as their socio-economic conditions allow them to improve their lifestyle, but reports reveal that poverty is the principal obstacle in using advanced and cleaner fuels. The slower development cycle in many parts of the world shows that biomass fuels will be utilized by poor households for decades ahead [9]. If we look at the stats provided by The Energy Progress Report 2019 [10], the global access to clean cooking was 58\% in the year 2014, and it reached only $59 \%$ in the year 2016 . The average growth rate was only $0.5 \%$ annually; unfortunately, it has been declining since the year 2010. With this annual rate of progress, it is not possible to meet the 2030 target of accessing cleaner fuels on universal level. In order to achieve the set goals, the annual growth rate must accelerate from 0.5 to $3 \%$ for the period 2016 to 2030 . However, with the present stats, the chances are that almost 2.3 billion people worldwide will not have direct access to clean cooking in 2030. It means the health impacts of IAP will also persist; especially in the areas with inadequate ventilation arrangements [10].

Ventilation plays an essential role in the measurement of indoor air quality (IAQ). In case if proper ventilation arrangement is missing in building structures, the IAQ decreases and buildings become unhealthy to live. Studies reveal that IAP is observed as one of the major causes of increasing health issues associated with poor ventilation. As per a study conducted in few remote villages of Palpa district located in the western part of Nepal, the percentage deficit in ventilation is $80 \%$ as compared to the minimal rate suggested by the American Society of Heating, Refrigeration and Air Conditioning Engineers [11]. Another study report that poorly ventilation kitchens in Nepal have 100 times higher concentration of total suspended particles in comparison to the standard prescribed limit and it is due to excessive smoke generation in the premises [12]. Parajuli et al. [11] also monitored the impact of traditional cooking systems and improved cooking systems in the village houses. The estimated reduction of $\mathrm{CO}$ concentration and $\mathrm{PM}_{2.5}$ concentration was 30 and $39 \%$ respectively, with the use of improved cooking systems as compared to traditional cooking systems. Generally, the occupational and educational stats along with housing conditions in urban areas are relatively better when compared to the rural areas. These conditions have a direct relationship with the choice of fuel for household needs and consequently have a significant impact on IAQ.

Reports reveal that poor IAQ is the second major factor for the higher mortality rate in India. It causes around 1.3 million deaths per year in the country. It is observed that out of $70 \%$ of the rural population in India [13], almost $80 \%$ of the people rely on biomass fuel to fulfill their household requirements [14]. The estimated number of people using harmful fuels for cooking in
India is highlighted in Fig. 1 [15]. It means that the largest population of the country lacks access to cleaner and efficient sources of fuel for cooking needs. Kerosene and biomass cooking fuels are also the principal causes of stillbirth in developing countries. Studies reveal that around $12 \%$ of stillbirths can be easily prevented by using cleaner cooking fuel for the household needs in India. Similar studies conducted in other developing countries such as Bangladesh, Nepal, Kenya, and Peru show that IAP is causing severe health hazards. Hence it has become necessary to address the challenges, especially for indoor cooking in the rural sectors. Lack of knowledge and understanding of the benefits of cleaner cooking solutions is the principal cause of adverse health consequences. It is essential to design some efficient and affordable household cooking solutions over traditional stoves, and it can be done only after studying behavioral patterns of the low-income population in the country.

The economic enhancements contribute to reducing IAP caused by various biomass fuels. However, the modern lifestyle is also leading to poor indoor environmental quality. With the improvement in the standard of living, most people are using indoor heating and cooling systems instead of natural ventilation systems [4]. This scenario has increased the cases of Sick Building Syndrome (SBS) somewhere around 30 to 200\% [16]. Studies reveal that factors affecting indoor environment include the rate of air exchange, humidity, temperature, ventilation, air movement, biological pollutants, particle pollutants, and gaseous pollutants [17]. Buildings currently constructed are more airtight and make use of advanced insulation materials that help to reduce the loss of energy. However, the air conditioning systems and the latest building envelope also cause a reduction in the circulation of fresh air. Meanwhile, the increasing consumption of chemical products and synthetic materials in indoor environments has increased the presence of several Volatile Organic Compounds (VOC). It is one of the principal causes of hypersensitivity [18]. So, it is fair to say that we are still not safe from hazards associated with IAP.

To deal with the increased mortality and morbidity rate due to IAP, numerous researchers are developing indoor environmental quality monitoring systems. Most of the people spend 80 to $90 \%$ of their time indoors either at home or in the offices. Thus, it is necessary to take immediate steps to improve the quality of indoor air. The idea is to create some healthy solutions that can contribute to a comfortable living environment while reducing the chances of the occurrence of severe diseases. This paper puts some light in the direction of efforts made by early researchers to deal with the challenges associated with IAP.

The remaining parts of this review paper are organized below in three different sections, where section of "Indoor 


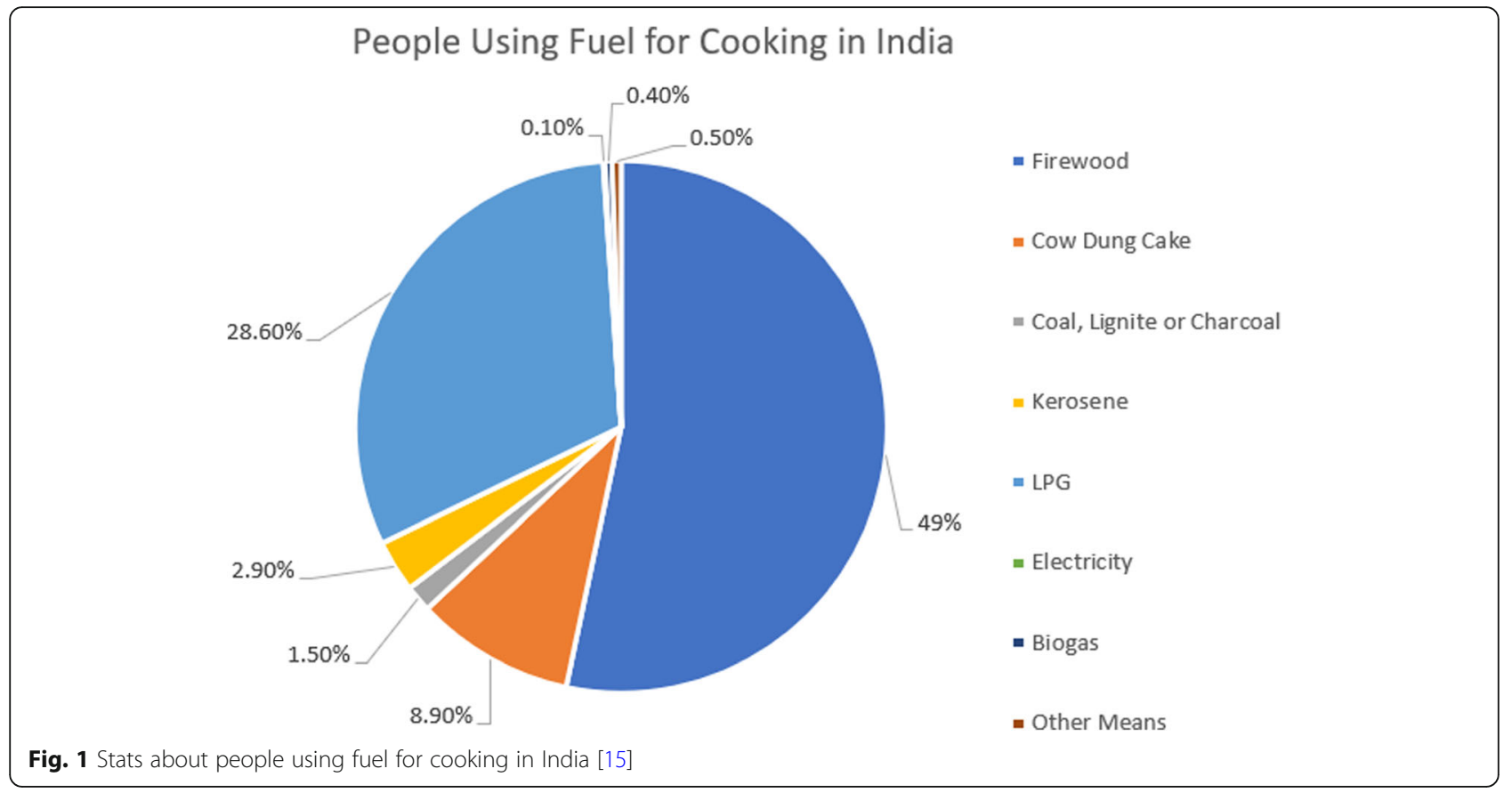

air quality and public health" describes the real-time cases of health impacts of IAP in developing countries along with the effect of various pollutants on public health. Section of "indoor air quality monitoring systems" presents an overview of some IAP monitoring systems developed in the past few years. The following section (Results/Discussion) provides a critical analysis of existing systems, along with the advantage and disadvantages of various technologies and sensor networks. Finally, the brief conclusion with future scopes of this study is given in the last section. This paper highlights the background of IAQ, primarily focusing on developing countries along with the potential ideas proposed for monitoring systems by different researchers. It is expected to guide future researchers to focus on new developments by considering the pros and cons of existing systems.

\section{Indoor air quality and public health $I A Q$ and rural health}

Several studies have been reported in India regarding the harmful impacts of IAP. In a nationally representative case-control study published in the year 2010 [19], after adjusting all essential living conditions and demographic factors, excessive exposure to solid fuel increased the number of deaths among children in the age group of 1 to 4. It is because these infants are used to spend more time indoors with their mothers. The prevalence ratio presented in this study for girls was 1.33; $95 \%$ Confidence Interval (CI): 1.12-1.58 and for boys: 1.30; 95\% CI: 1.081.56. Solid fuel was also reported as the most significant reason behind many cases of non-fatal pneumonia with a prevalence ratio of 1.94; 95\% CI: $1.13-3.33$ for girls and 1.54; $95 \%$ CI: $1.01-2.35$ for boys [19].

Another case study [20] reveals that routine exposure to fuel other than liquid petroleum gas is directly linked to acute infections in the lower respiratory tract. The adjusted Odds Ratio $=4.73$; 95\% CI: $1.67-13.45$, and these stats were obtained even after adjusting the rest of the risk factors. According to this study, out of the total number of children affected with acute lower respiratory tract infection; almost $24.8 \%$ were affected by pneumonia, $45.5 \%$ suffered from severe pneumonia whereas, the other $29.7 \%$ were observed to have a severe disease [20]. Furthermore, biomass fuel usage in India is also associated with prolonged nasal mucociliary clearance time. It was recorded to be $766 \pm 378 \mathrm{~s}$, whereas this time is reported to be $545 \pm 216 \mathrm{~s}$ in the case of clean fuel users [21]. If we look at 2018 Environmental Performance Index Results, India ranked 177th among 180 countries; whereas, other developing countries like Nepal and Bangladesh ranked 176th and 179th respectively [22]. These stats reveal that some serious efforts are required to improve building health in most developing countries.

\section{$I A Q$ and potential pollutants}

IAQ is determined by the concentration of several pollutants such as particle matter, primary, and secondary gaseous pollutants. Studies reveal that a higher number of PM in the urban indoor environment is observed to be of ultra-fine size. Typically, smaller than $0.1 \mu \mathrm{m}$, whereas the particles with a size larger than $0.1 \mu \mathrm{m}$ are 
observed to be present in a short amount, somewhere below the $10 \%$ concentration level $[23,24]$.

The list of primary gaseous pollutants includes radon, $\mathrm{O}_{3}$, Nitric oxides (NOx), Sulphur dioxide $\left(\mathrm{SO}_{2}\right)$, $\mathrm{CO}$, Diatomic carbon, and VOCs. Within the past few years, the usage of chemical products in indoor environments has been increased drastically. These chemical materials generate several hazardous chemical pollutants under room temperature including VOCs. These compounds can cause several health issues with symptoms such as nausea, headache, dizziness, tiredness, nose, eye, and throat irritations [25]. Ground-level ozone is a colorless gas that acts as an integral component of the atmosphere and is the leading cause of several health diseases related to the respiratory system [25]. Common symptoms of $\mathrm{CO}$ poisoning include vomiting, nausea, weakness, dizziness, headache, and loss of consciousness. $\mathrm{SO}_{2}$ is a highly reactive and colorless gas that plays an essential role in the atmosphere. It is harmful to human health and the patients that are already suffering from lung disease, older people, children, as well as those who face regular exposure to $\mathrm{SO}$, are at higher risks of developing lung diseases and skin related problems. Nitrogen oxide is the leading cause of several infections associated with the respiratory system. Some of the most commonly observed symptoms of $\mathrm{NO}_{2}$ toxicity include wheezing, coughing, bronchospasm, fever, diaphoresis, chest pain, dyspnea, headache, throat irritations, and pulmonary edema [26]. $\mathrm{CO}_{2}$ is a by-product of combustion and is also produced by the metabolic process of living organisms. Several studies reveal that a moderate concentration of $\mathrm{CO}_{2}$ in indoor air can cause fatigue and headaches, whereas higher levels lead to vomiting, dizziness, and nausea. Loss of concentration can also occur at too high levels of $\mathrm{CO}_{2}$ [27].

Higher concentration of VOCs in buildings can irritate skin, throat, nose, and eyes. Medical health experts also report a broader set of illnesses due to VOCs, such as headaches, respiratory symptoms, fatigue and SBS [28].

The mixture of various pollutants present in the indoor air can cause a chain of chemical reactions, and it further generates secondary pollutants in the environment. Studies reveal that these secondary pollutants are more harmful when compared to the primary ones [29, 30]. Indoor secondary pollutants (such as ozone, $\mathrm{NO}_{2}$, sulphur trioxide) are observed to cause significant discomfort and a harmful impact on human health. Moreover, they are challenging to measure and predict due to the complexities involved in their composition [27]. Volatile, nonvolatile, and non-biological agents cause a harmful impact on indoor air while degrading the overall quality of the environment. The list of biological organisms includes dust mites, pollen, mildew, fungi, molds, bacteria, and many insects, animal dander, anthropoid, infectious agents, pollen, mycotoxins, infectious agents, and animal saliva. The dangerous combination of several indoor air allergens with specific outdoor allergens such as molds, grass pollen, animal allergens, cockroaches, and smoking cause risks of allergic sensitization, asthma and many other respiratory diseases [31]. The list of major indoor air pollutants, sources of emission, and associated medical health consequences is shown in Table 1.

\section{Indoor air quality monitoring (IAQM) systems}

Currently, the increasing health issues due to IAP are an essential matter of discussion for researchers worldwide. Some professionals utilized advanced sensor networks and communication technologies to propose IAQ monitoring systems for the enhanced living environment. As researchers are actively working in this field to improve building health, it is difficult to review all existing and proposed IAQ monitoring systems in this paper. Nonetheless, this section includes studies based on the most prominent IAP parameters. As automatic alert systems are need of the hour in our busy schedules, we have preferably picked monitoring systems that propose online access to recorded environmental factors or generate SMS based alerts. Although several techniques have been invented for real-time monitoring, the preference to be reviewed was given to Wireless Sensor Network (WSN) and Internet of Things (IoT) based models due to their rising scope in the Industry 4.0 revolution.

Alhmiedat and Samara [32] developed a low-cost ZigBee sensor network architecture to monitor IAQ in realtime. It is possible to install four sensor nodes in the indoor environment and collect data for more than four weeks. The environmental data were further transferred for analysis via a ZigBee communication protocol. Authors of this paper analyzed $\mathrm{CO}_{2}$, benzene, $\mathrm{NOx}$, and ammonia for IAQ assessment at the time of cooking in the kitchen, while other sensors collected desired input from the bedroom, living room and office area. It provides real-time monitoring of all factors contributing to indoor air; however, few developments to this system can be still made by reducing power consumption and improving the accuracy of monitored parameters.

Wu et al. [33] worked on mobile microscopy and machine learning methods to perform accurate quantification and impact analysis of PM. The authors demonstrated a cost-effective and portable PM imaging, quantification and sizing model named C-Air, and the results were displayed on a mobile-based app. A remote server was used for automated processing of essential digital holographic microscope images that ensues accurate PM measurements. This system was capable of providing valuable statistics about density distribution and particle size with the sizing accuracy of approximately $93 \%$. C-Air can be customized to detect specific air particles such as mold and 
Table 1 Major pollutants affecting the quality of indoor air and the common sources of emission

\begin{tabular}{|c|c|c|}
\hline Pollutants & Major Sources of Emission & Associated Medical Health Consequences \\
\hline $\mathrm{SO}_{2}$ & $\begin{array}{l}\text { Fossil fuel combustion such as oil, coal and } \\
\text { natural gas, outdoor air }\end{array}$ & Acute exposure leads to bronchial activity. \\
\hline $\mathrm{CO}$ & $\begin{array}{l}\text { Tobacco smoke, stoves, boilers, kerosene or } \\
\text { gas heaters, fuel burning }\end{array}$ & Low birth weight, Increase in perinatal deaths \\
\hline $\mathrm{CO}_{2}$ & $\begin{array}{l}\text { Combustion activities, metabolic activity and } \\
\text { motor vehicle in garages }\end{array}$ & $\begin{array}{l}\text { Headaches, sleepiness, Poor concentration, Loss of } \\
\text { attention }\end{array}$ \\
\hline Fungal Spores & Internal surfaces, foodstuffs, plants and soil & $\begin{array}{l}\text { Asthma episodes, Allergic reactions, Eye, throat and nose } \\
\text { irritation, Sinus and other respiratory problems }\end{array}$ \\
\hline Radon & $\begin{array}{l}\text { Soil Building concentration materials such as } \\
\text { stone and concrete }\end{array}$ & Risk of lung cancer, Breathing problems \\
\hline Asbestos & Insulation, fire retardant materials & $\begin{array}{l}\text { Cancers such as mesothelioma, Pleural thickening, Pleural } \\
\text { plaques and asbestosis }\end{array}$ \\
\hline $\mathrm{NO}_{2}$ & $\begin{array}{l}\text { Motor vehicles in garages, fuel burning and } \\
\text { outdoor air }\end{array}$ & $\begin{array}{l}\text { Exacerbation of asthma and wheezing, Reduced lung } \\
\text { function in kids, Respiratory infections }\end{array}$ \\
\hline Pollens and allergens & $\begin{array}{l}\text { Outdoor air, plants, weeds, grass, trees, } \\
\text { insects, domestic animals, and house dust }\end{array}$ & Trigger symptoms of allergy \\
\hline $\begin{array}{l}\text { Particles (small particles }<10 \mu \mathrm{m} \text {; } \\
\text { and }<2.5 \mu \mathrm{m} \text { aerodynamic diameter) }\end{array}$ & $\begin{array}{l}\text { Tobacco smoke, re-suspension, combustion } \\
\text { products }\end{array}$ & $\begin{array}{l}\text { Exacerbation of Asthma, Wheezing, Respiratory infections, } \\
\text { Exacerbation of COPD, Chronic bronchitis and COPD }\end{array}$ \\
\hline Ozone & Photochemical reactions & $\begin{array}{l}\text { Airway irritation, Permanent lung damage, Pneumonia and } \\
\text { bronchitis, Aggravate asthma }\end{array}$ \\
\hline Lead & $\begin{array}{l}\text { Paints, firearms, lead bullets, dust, soil, radiators, } \\
\text { consumer products }\end{array}$ & $\begin{array}{l}\text { Memory loss, Hearing loss, Damage to the nervous system } \\
\text { in new-borns, High blood pressure, Kidney } \& \text { heart disease, } \\
\text { Reduced fertility, Hyperactivity or loss of consciousness }\end{array}$ \\
\hline VOCs & $\begin{array}{l}\text { Burning of gas, wood, and kerosene, cleaning } \\
\text { agents, paints, hair spray, perfumes and tobacco } \\
\text { smoke }\end{array}$ & $\begin{array}{l}\text { Allergic skin reactions, Visual disorders and memory } \\
\text { impairments, Damage to the central nervous system, kidney, } \\
\text { and liver, Decline in serum, cholinesterase levels, SBS }\end{array}$ \\
\hline
\end{tabular}

pollens. The performance of C-Air was tested for indoor as well as outdoor air environments.

Zampolli et al. [34] developed a low-cost model with an electronic nose based solid-state sensor array for monitoring IAQ. By using a combination of advanced pattern recognition techniques and optimized gas sensor array, researchers targeted the quantification of $\mathrm{NOx}$, $\mathrm{CO}$, along with VOCs and relative humidity $(\mathrm{RH})$. The performance of the electronic nose was analyzed in real operating conditions where $\mathrm{NO}_{2}$ concentrations at 20 $\mathrm{ppb}$ and $\mathrm{CO}$ at $5 \mathrm{ppm}$ were monitored continuously for at least $45 \mathrm{~d}$. This approach helped to identify the presence of individual pollutants along with the mixture of different contaminants in the test environment. This system was found feasible enough to detect $\mathrm{NO}_{2}$ and $\mathrm{CO}$ levels in indoor air, and these results were further used to manage the appropriate usage of heating, ventilation, and air conditioning (HVAC) systems in the indoor environment without disturbing the air quality.

Kim et al. [35] focused on seven gases $\left(\mathrm{CO}_{2}\right.$, VOCs, $\mathrm{SO}_{2}, \mathrm{NOx}, \mathrm{CO}, \mathrm{PM}$, and ozone) to test IAQ in real-time. The experiments were conducted in three different settings: big church, medium size classroom, and small size living room to test the impact of different factors on IAQ. Researchers concluded that so many factors contribute to altering the quality of indoor air. Some of these are wind, location, airflow, the density of people and room size. However, it was found that gas sensors consume lots of power, so it is important to apply critical thinking for the selection of appropriate sensor nodes. Future researchers are also advised to work on environmental settings and sensor characteristics to ensure reliable calibration of the system to obtain accurate results.

$\mathrm{Yu}$ and Lin [36] constructed an intelligent wireless sensing and control system to deal with health issues caused by IAP. The system is made up of three different parts: 1) Data acquisition that helps in obtaining values about environmental indicators such as $\mathrm{CO}_{2}$ concentration, $\mathrm{RH}$, and temperature through polling mechanism; 2) Data analysis, responsible for collecting data and interfacing with the AutoRegressive Integrated Moving Average (ARIMA) prediction model to analyze air quality trends in the premises; and 3) Data feedback to trigger necessary actions based on fuzzy results. It may send a warning message or may control the speed of the fan automatically. Each sensor node in this hardware architecture is powered by the IEEE1451.4 standard, and the communication channel is established by ZigBee technology. The software architecture is precisely separated into three different sections where 1) Data monitoring agent creates a bridge between software and hardware, 
2) Air quality analyzing agent takes care of air quality trends and triggers relevant actions for higher pollution levels; and 3) Application agent provides services for data display automatic control and alerts. The final ARIMA prediction model based IAQ monitoring system was deployed in the real-time environment at nine different areas of Taiwan. It included Environmental Protection Administration, university, and elementary schools. The performance of the system was further tested using two tests: Validation of the accuracy of the prediction model and validation of energy-saving performance. The system used to make useful decisions about ventilation equipment in the premises depending upon the threshold level of air quality parameters.

Pillai et al. [37] implemented a sensor network for IAQ monitoring using the Controller Area Network (CAN) interface. In order to run the experiment on a real-time basis, the sensors were distributed in a specific area, and a serial standard bus communication network was used for information exchange between them. CAN is a specially designed high integrity serial bus protocol that works on high speed by supporting information exchange rate between $20 \mathrm{kbit} \mathrm{s}^{-1}$ to $1 \mathrm{Mbit} \mathrm{s}^{-1}$. Using CAN, researchers were able to develop a highly reliable, efficient, and economical communication link between display nodes and sensor nodes. The hardware tests provided highly accurate monitoring for IAQ with short processing time.

Abraham and Li [38] proposed a cost-effective WSN system for monitoring IAQ. The system was designed using low-cost micro gas sensors $\left(\mathrm{CO}, \mathrm{VOC}\right.$, and $\mathrm{CO}_{2}$ ) and use the Arduino microcontroller as the processing unit. The mesh network for this monitoring system was developed using the ZigBee module that promised low power, low cost and wireless solution for communication. Data calibration for micro gas sensor networks was further performed using Least-Square Method. It helped researchers to study the current status of IAQ while collecting valuable data for the long-term impacts of bad air quality on human health. The proposed system was also compared with standard GrayWolf System, and it was observed to be independent of humidity and temperature variations.

Cheng et al. [39] developed AirCloud that is a cloudbased air quality monitoring system designed to serve low cost personal and pervasive needs. The authors worked on two types of Internet-connected PM monitors (focused around $\mathrm{PM}_{2.5}$ levels) that were named as mini air quality monitoring (AQM) and AQM. The monitoring process was based entirely upon the mechanical structures that were designed for maintaining optimal airflow. On the cloud side, the authors created an air quality analytics engine to learn and develop models of measured air quality with the help of sensors. This cloud-based engine helped in the calibration of mini AQMs and AQMs on a real-time basis while inferring $\mathrm{PM}_{2.5}$ concentrations. This system provided relevant accuracies at lower cost ensuring dense coverage ability.

Kang and Hwang [40] introduced an air quality monitoring system to test the relevance of the Comprehensive Air Quality Index for accurate IAQ assessment. The authors also proposed a real-time Comprehensive Indoor Air Quality Indicator (CIAQI) system that can work effectively against all dynamic changes and is quite efficient in processing ability along with memory overhead. In order to develop the experimental setup for realistic indoor air environment monitoring, the authors used VOC, $\mathrm{PM}_{10}, \mathrm{CO}$, temperature and humidity sensors. The authors also compared the proposed system performance with absolute concentration of all considered pollutants used for ambient air quality index (AQI) with Simple Moving Average scheme and observed that the proposed CIAQI system is more adaptive to real-time changes in the IAQ. Also, this system utilized small memory; therefore, it was considered as an economical solution for the IoT based air quality monitoring.

Bhattacharya et al. [41] developed a wireless system for monitoring IAQ by working on a few essential parameters such as humidity, temperature, gaseous pollutants, and PM. This system determines indoor environment health in terms of the AQI and at the same time gives real-time inputs to control HVAC systems. In order to serve the smart building applications, authors have also developed a toolkit that measures live air quality data in the form of graphs and numbers.

Ahn et al. [42] designed a microchip by utilizing six atmospheric sensors: VOCs, light quantity, humidity, temperature, fine dust, and $\mathrm{CO}_{2}$. The atmospheric changes were estimated using deep learning models. Performance of the proposed Gated Recurrent Network (GRU) model was also compared with other models such as Long ShortTerm Memory (LSTM) networks and linear regression, where the proposed system presented better performance with higher accuracy of $85 \%$ over a variety of parameter settings.

Pitarma et al. [43] developed a low-cost IAQ monitoring unit using a WSN system in combination with microsensors, XBee modules, and Arduino. They worked on five major IAP parameters: luminosity, $\mathrm{CO}_{2}, \mathrm{CO}$, humidity and air temperature while performing real-time monitoring on a web portal. The wireless communication network between sensors and gateway was established with the XBee module utilizing ZigBee networking protocol and IEEE802.15.4 radio standards. Sensors involved in realtime measurement were sensor SHT10 for $\mathrm{RH}$ and temperature; MQ7 for $\mathrm{CO}$, T6615 sensor for $\mathrm{CO}_{2}$ measurement and LDR5 $\mathrm{mm}$ for light detection. The web interface was designed using MySQL database and Personal 
Home Page (PHP). The prime goal to design this system was to help users get instant updates about exposure risks in the living environment.

Benammar et al. [44] designed an end to end IAQM system using WSN technology. It was focused around the measurement of $\mathrm{RH}$, ambient temperature, $\mathrm{Cl}_{2}, \mathrm{O}_{3}, \mathrm{NO}_{2}$, $\mathrm{SO}_{2}, \mathrm{CO}$, and $\mathrm{CO}_{2}$. The sensor nodes were made to communicate to the gateway via $\mathrm{XBee} \mathrm{PRO}$ radio modules. The sensor nodes in this study include a set of calibrated sensor units, a data storage unit named Waspmote, and sensor interface board known as Gas Pro sensor board. The prime role of the gateway in this study was to process the IAQ data collected from target sites and perform reliable dissemination via a web server. This system was adapted to open source IoT web server platform, named Emoncms to ensure long-term storage as well as live monitoring of IAQM data. Seamless integration of smart mobile standards, WSN, and many other sensing technologies is performed to design the ultimate scalable smart system to monitor IAP. In order to meet the power requirements of the system, authors also designed separate battery units for the sensor network.

Saad et al. [45] created a system to monitor various environmental parameters that are directly related to air quality. They focused on $\mathrm{RH}$, temperature, PM, and gaseous pollutants that have a direct impact on human health. A WSN was used to measure data from the target location, and it was transferred to the base station via the WSN node. A self-developed server program on the computer system used to access and process this data to analyze IAQ on a real-time basis.

Tiele et al. [46] focused on the design and development of a portable and low-cost indoor environment monitoring system. This study was performed on a few essential parameters of indoor air such as sound levels, illuminance, $\mathrm{CO}, \mathrm{CO}_{2}, \mathrm{VOCs}, \mathrm{PM}_{10}, \mathrm{PM}_{2.5}, \mathrm{RH}$, and temperature. The experiments were conducted in both indoor work environments and outdoors. The authors defined an Indoor Environment Quality (IEQ) index to estimate the overall percentage of IEQ.

Moreno-Rangel et al. [47] presented a study to assess usability, accuracy, and the precision of low-cost IAQ monitor within a residential building. After analyzing the cost and complexity related issues associated with existing scientific solutions for IAQ monitoring, the authors proposed a reliable and low-cost system for households. They focused on a few essential parameters, such as $\mathrm{PM}_{2.5}, \mathrm{CO}_{2}$, VOCs, $\mathrm{RH}$, and temperature. All sensors were calibrated before installation to ensure an adequate measurement. The collected data was analyzed using FOOBOT monitors based on the percentage of time the pollutant levels crossed the threshold levels set by World Health Organization. In order to enhance the accuracy of the measurement, authors in this study used IBM SPSS Statistics to perform statistical analysis.

Idrees et al. [48] closely observed the challenges associated with IAP and developed an Arduino based platform for real-time IAQ monitoring systems. They initiated steps toward the detailed investigation of factors such as computational complexity, infrastructure, issues, and procedures for efficient designing. The prototype for the proposed real-time IAQ monitoring system was designed using the IBM Watson IoT platform and Arduino board. The authors worked on eight parameters that have a considerable impact on human health in the building environment. The list includes $\mathrm{RH}$, temperature, $\mathrm{O}_{3}, \mathrm{SO}_{2}, \mathrm{NO}_{2}, \mathrm{CO}, \mathrm{PM}_{2.5}$, and $\mathrm{PM}_{10}$. The significant advantage of this system was its ability to reduce the computational burden of the sensing nodes by almost $70 \%$, leading to longer battery life. In order to ensure higher accuracy for measurements, authors used standard calibration procedures on sensor networks, and a data transmission strategy was used to minimize the power consumption along with redundant network traffic. The three most essential layers of the proposed monitoring system were sensing layer, edge computing layer, and application layer. This model reported a reduction of $23 \%$ in the overall power consumption, and the performance was validated by setting the system in different environments.

Sivasankari et al. [49] proposed an IoT based system to monitor IAQ, and the analysis was performed using a Raspberry Pi model. The parameters included in this study were $\mathrm{RH}$, temperature, $\mathrm{NO}_{2}, \mathrm{CO}$, and concentrations of smoke. The measurements were done using MQ series sensors, Mics $2714 \mathrm{NO}_{2}$ sensor, LM-35, and DHT11 sensor. An analog to digital converter was also added to the system so that sensors can be directly interfaced with the Raspberry pi module via eight different channels. This system was used to generate an alarm for indicating a high concentration of emissions, such as a warning for the air pollution rate in the premises.

Arroyo et al. [50] presented an air quality measurement system made of a distributed sensor network and cloud-based WSN system. Low power ZigBee motes were used for collecting field data, and an optimized cloud computing system was implemented for processing, monitoring, storing, and visualizing received data. This laboratory study was based on the measurement of VOCs, including xylene, ethylbenzene, toluene, and benzene. Multilayer perceptron, principle component analysis, support vector machine, and backpropagation learning algorithm were used at the data processing stage.

This section summarizes the review of IAP monitoring systems that are proposed by early researchers from different countries in the past few years. The main idea is 
to discuss potential techniques, architectures, and configurations that are already used by researchers. Reliable and efficient monitoring systems can be used in urban as well as rural areas to monitor the IAP and its impact on residents. It is believed that instant alerts can guide people to make proper ventilation arrangements by opening windows or doors in the kitchen; such systems are more useful in homes having traditional cooking systems, and inadequate ventilation arrangements. The results and discussion section further provide a detailed analysis of these studies while covering the strengths, weaknesses of the existing IAQ monitoring systems along with future scopes to guide future researchers.

\section{Results and discussion WSN based systems}

The trends in the development of the IAQ monitoring system reveal that most of the researchers in the past few years have worked on WSN based designs with ZigBee as the most reliable communication protocol. The ATmega microcontroller manages the real-time data collection; however, Raspberry $\mathrm{Pi}$ is another common choice for setting up a sensor network in the target environment. WSN is an Ad Hoc Network, where sensor networks consume immense energy while transmitting data in multiple hops. The time taken by sensors to send a signal to the monitoring unit was observed to be considerably high. In such situations, researchers needed to work on battery power management to improve overall system performance. However, only a few researchers, such as Yu and Lin [36] were successful in implementing energy-saving and cost-saving monitoring systems using WSN architecture. Trends reveal that most of the WSN based IAQ monitoring systems use web servers as data access platforms; it demands additional efforts to generate real-time alerts on user smartphones to prevent hazardous conditions. Table 2 highlights the summary of WSN based IAQ monitoring systems.

\section{IoT based systems}

Considering the battery life expectancy and reliable singlehop communication abilities, IoT monitoring systems are believed to be the most reliable solutions for IAQ measurement. With lower latencies and lesser power consumption, these systems also demand lesser efforts for maintenance. IoT based real-time monitoring systems are known as smart systems; consequently, most of the researchers and industrial manufacturers are more attracted to this architecture. Experts reveal that the IoT system can monitor a large number of parameters, even without compromising system performance. Studies carried by Idrees et al. [48] and Sivasankari et al. [49] gave a new edge to the IAQ monitoring systems with impactful IoT architecture design. However, very few researchers in the past few years have worked on prediction systems in the field of IAQ monitoring. Studies reveal that it is much easier to combine IoT monitoring systems to machine learning and deep learning networks to initiate reliable prediction decisions. It is a significant area of work for new age researchers. Table 3 presents a summary of IoT based IAQ monitoring systems.

\section{Other technologies}

Some researchers also worked on architectures other than WSN and IoT, but few parameters reveal the low performance of such systems as compared to the potential of IoT systems for real-time monitoring. The most significant disadvantage of the C-Air platform presented by $\mathrm{Wu}$ et al. [33] was that this study was limited to PM levels only; but in the real world, IAQ is affected by many other pollutants as well. Zampolli et al. [34] tried working on multiple pollutants, but the study was limited to the simulation environment only; the practical implementation of such systems is the real challenge. Moreover, these researchers worked on low-cost sensors where calibration is a significant challenge, and it leads to a lack of performance for the overall design. Similar constraints were found with the approach followed by Pillai et al. [37], where the system was studied on breadboards in a controlled lab environment only. Cheng et al. [39] tried to implement a prediction model with CAN interface, but the study was again limited to PM levels only; the impact of other pollutants was not considered in this study. Moreno-Rangel et al. [47] presented a valuable study with FOOBOT monitors, and they considered multiple IAQ parameters for the realtime analysis, but the sensor calibration was again a relevant challenge to ensure desired performance. Table 4 presents a summary of IAQ monitoring systems based on architectures other than WSN and IoT.

\section{Discussion and critical analysis}

The primary requirement at present is to perform realtime monitoring of IAQ parameters and generate alerts to the building occupants to avoid hazardous conditions. The IoT approach has great potential in this direction to ensure lesser power consumption, negligible time delays, and has a better ability to interact with the physical world.

One of the prime concerns in the development of IAQ systems is the higher cost and massive power consumption of sensor nodes. If we consider the real-time applications of IAQ systems, the sensor units are usually installed in an industrial environment, inside homes, offices, and outdoor areas as well. However, in all these cases, the design of the sensor unit demands more focus on size, design cost, power consumption, communication protocol, and performance dependence on temperature and humidity variations. Sensor calibration is currently the main 
Table 2 Summary of IAQ monitoring systems based on WSN

\begin{tabular}{|c|c|c|c|c|c|c|c|c|}
\hline $\begin{array}{l}\text { Sr. } \\
\text { No. }\end{array}$ & References & Year & $\begin{array}{l}\text { Parameters } \\
\text { Considered }\end{array}$ & Architecture & $\begin{array}{l}\text { Communication } \\
\text { Interface }\end{array}$ & MCU & Data Access & Remarks \\
\hline 1. & $\begin{array}{l}\text { Alhmiedat } \\
\text { and Samara } \\
\text { [32] }\end{array}$ & 2017 & $\begin{array}{l}\mathrm{CO}_{2} \text {, benzene, } \mathrm{NO}_{x} \\
\text { and ammonia }\end{array}$ & WSN & ZigBee & $\begin{array}{l}\text { ATtiny } 85 \\
\text { microcontroller }\end{array}$ & $\begin{array}{l}\text { Simulation } \\
\text { environment }\end{array}$ & $\begin{array}{l}\text { A sleep state algorithm } \\
\text { and interface circuit used to } \\
\text { minimize power consumption }\end{array}$ \\
\hline 2. & $\begin{array}{l}\text { Kim et al. } \\
{[35]}\end{array}$ & 2014 & $\begin{array}{l}\mathrm{CO}_{2}, \mathrm{VOCs}, \mathrm{SO}_{2}, \mathrm{NO}_{x \prime} \\
\mathrm{CO}, \mathrm{PM} \text { and } \mathrm{O}_{3}\end{array}$ & WSN & ZigBee & Raspberry Pi & $\begin{array}{l}\text { Web server and } \\
\text { Mobile }\end{array}$ & $\begin{array}{l}\text { Experiments conducted in three } \\
\text { different settings: big church, } \\
\text { medium size classroom and } \\
\text { small size living room; Real-time } \\
\text { monitoring alert }\end{array}$ \\
\hline 3. & $\begin{array}{l}\text { Yu and Lin } \\
{[36]}\end{array}$ & 2015 & $\begin{array}{l}\mathrm{CO}_{2}, \mathrm{RH} \\
\text { temperature }\end{array}$ & WSN & ZigBee & Not available & $\begin{array}{l}\text { Web Pages and } \\
\text { Mobile App }\end{array}$ & $\begin{array}{l}\text { Use of ARIMA Model for } \\
\text { prediction, System provided } \\
55 \% \text { reduction to the sensor } \\
\text { network energy consumption } \\
\text { with Fuzzy Log-c based } \\
\text { decision model }\end{array}$ \\
\hline 4. & $\begin{array}{l}\text { Abraham } \\
\text { and Li [38] }\end{array}$ & 2014 & $\begin{array}{l}\mathrm{CO}, \mathrm{VOC} \text { and } \mathrm{CO}_{2} \\
\mathrm{O}_{3}, \mathrm{RH} \text {, temperature, }\end{array}$ & WSN & ZigBee module & $\begin{array}{l}\text { Arduino Uno } \\
\text { microcontroller }\end{array}$ & Web Server & $\begin{array}{l}\text { Micro gas sensors were } \\
\text { calibrated using least square } \\
\text { estimation-based method }\end{array}$ \\
\hline 5. & $\begin{array}{l}\text { Bhattacharya } \\
\text { et al. [41] }\end{array}$ & 2012 & $\begin{array}{l}\text { RH, temperature, } \\
\text { gaseous pollutants } \\
\text { and PM }\end{array}$ & WSN & ZigBee module & $\begin{array}{l}\text { ATmega1281 } \\
\text { (Waspmote) }\end{array}$ & $\begin{array}{l}\text { HVAC control } \\
\text { application, SMS } \\
\text { and email-based } \\
\text { alerts can be } \\
\text { generated on } \\
\text { subscription. }\end{array}$ & $\begin{array}{l}\text { Context-Aware Framework was } \\
\text { designed to connect sensors } \\
\text { with applications. }\end{array}$ \\
\hline 6. & $\begin{array}{l}\text { Ahn et al. } \\
\text { [42] }\end{array}$ & 2017 & $\begin{array}{l}\text { VOC, light quantity, } \\
\mathrm{RH} \text {, temperature, } \\
\text { fine dust, } \mathrm{CO}_{2}\end{array}$ & WSN & $\begin{array}{l}\text { UART/I2C, } \\
\text { ESP8266 Wi-Fi } \\
\text { Module }\end{array}$ & ATmega328P & Linux Server & $\begin{array}{l}\text { Comparative prediction models } \\
\text { were designed using LSTM and } \\
\text { GRU networks }\end{array}$ \\
\hline 7. & $\begin{array}{l}\text { Pitarma } \\
\text { et al. [43] }\end{array}$ & 2016 & $\begin{array}{l}\text { Luminosity, } \mathrm{CO}_{2,} \\
\mathrm{CO}, \mathrm{RH} \text { and air } \\
\text { temperature }\end{array}$ & WSN & ZigBee module & Arduino & Web portal & $\begin{array}{l}\text { A dedicated web portal named } \\
\text { as iAQ was designed using PHP } \\
\text { to access system data }\end{array}$ \\
\hline 8. & $\begin{array}{l}\text { Benammar } \\
\text { et al. [44] }\end{array}$ & 2018 & $\begin{array}{l}\mathrm{RH} \text {, ambient } \\
\text { temperature, } \mathrm{Cl}_{2}, \mathrm{O}_{3 \prime} \\
\mathrm{NO}_{2}, \mathrm{SO}_{2}, \mathrm{CO}, \mathrm{CO}_{2}\end{array}$ & WSN & $\begin{array}{l}\text { ZigBee Pro radio } \\
\text { module }\end{array}$ & $\begin{array}{l}\text { ATmega } 1281 \\
\text { (Waspmote), } \\
\text { Raspberry Pi2 } \\
\text { for core } \\
\text { gateway }\end{array}$ & $\begin{array}{l}\text { Open-source loT } \\
\text { web server } \\
\text { platform }\end{array}$ & - \\
\hline 9. & $\begin{array}{l}\text { Saad et al. } \\
{[45]}\end{array}$ & 2013 & $\begin{array}{l}\mathrm{RH} \text {, temperature, } \\
\mathrm{PM} \text { and gaseous } \\
\text { pollutants }\end{array}$ & WSN & $\begin{array}{l}\text { AT86RF230 } \\
\text { radio frequency } \\
\text { front end IC for } \\
\text { ZigBee standard }\end{array}$ & $\begin{array}{l}\text { ATmega } 1281 \\
\text { low power } \\
\text { MCU }\end{array}$ & $\begin{array}{l}\text { Web InterfacThe } \\
\mathrm{s}\end{array}$ & $\begin{array}{l}\text { Study was carried within the } \\
\text { Lab environment. }\end{array}$ \\
\hline 10. & $\begin{array}{l}\text { Tiele et al. } \\
{[46]}\end{array}$ & 2018 & $\begin{array}{l}\text { Sound levels, } \\
\text { illuminance, } \mathrm{CO} \text {, } \\
\mathrm{CO}_{2} \text {, total VOCs, } \\
\mathrm{PM}_{10}, \mathrm{PM}_{2.5}, \mathrm{RH} \\
\text { and temperature }\end{array}$ & WSN & I2C/UART & Feather Mo & $\begin{array}{l}\text { OLED Display, } \\
\text { MicroSD Card }\end{array}$ & $\begin{array}{l}\text { Made use of eNose for data } \\
\text { collection, Custom low-cost } \\
\text { sensor module was designed } \\
\text { using Altium Designer }\end{array}$ \\
\hline 11. & $\begin{array}{l}\text { Arroyo } \\
\text { et al. [50] }\end{array}$ & 2019 & $\begin{array}{l}\text { Toluene, } \\
\text { ethylbenzene, } \\
\text { benzene, and xylene }\end{array}$ & WSN & ZigBee & Not available & Cloud server & Laboratoy based case study \\
\hline
\end{tabular}

challenge in front of future researchers to ensure accurate real-time monitoring. Although Metal Oxide Semiconductor sensors are cheaper when compared to the optical and electromechanical sensors (some examples are TGS 2442 and TGS416), they work on the resistive heating; hence, consume loads of energy from limited battery unit of wireless motes. As a result, it reduces the overall lifetime of the network. A considerable solution to solve this problem is placing motes (a specific type of sensor node that can collect, process information and can communicate with other nodes in the network) in sleep mode when they are not working actively in the system. Some studies also reveal that a high-quality micro gas sensor can perform better in variable humidity and temperature conditions. One advanced solution to air quality monitoring is Mobile Sensing System for IAQ personalized mobile sensing system that is gaining popularity due to the portable, energy-efficient and inexpensive design. Most of the researchers have used ZigBee to establish a communication network between sensor nodes and 
Table 3 Summary of IAQ monitoring systems based on loT

\begin{tabular}{|c|c|c|c|c|c|c|c|c|}
\hline Sr. No. & References & Year & $\begin{array}{l}\text { Parameters } \\
\text { considered }\end{array}$ & Architecture & $\begin{array}{l}\text { Communication } \\
\text { Interface }\end{array}$ & MCU & Data Access & Remarks \\
\hline 1. & $\begin{array}{l}\text { Kang and } \\
\text { Hwang [40] }\end{array}$ & 2016 & $\begin{array}{l}\text { VOC, } \mathrm{PM}_{10,} \mathrm{CO}, \\
\text { temperature } \\
\text { and } \mathrm{RH}\end{array}$ & IoT & $\begin{array}{l}\text { Bluetooth, } \\
\text { Wi-Fi and RF } \\
\text { communication } \\
\text { module }\end{array}$ & TI MSP430 & Wb server & $\begin{array}{l}\text { Comprehensive Real-Time Indoor } \\
\text { Air-Quality Level Indicator was } \\
\text { designed }\end{array}$ \\
\hline 2. & $\begin{array}{l}\text { Idrees } \\
\text { et al. [48] }\end{array}$ & 2018 & $\begin{array}{l}\mathrm{RH}, \text { temperature, } \\
\mathrm{O}_{3}, \mathrm{SO}_{2}, \mathrm{NO}_{2}, \mathrm{CO}, \\
\mathrm{PM}_{2.5} \text { and } \mathrm{PM}_{10}\end{array}$ & loT & $\begin{array}{l}\text { ZigBee and Wi-Fi } \\
\text { ESP8266 }\end{array}$ & ATmega328P & $\begin{array}{l}\text { Web-based } \\
\text { IBM Watson loT } \\
\text { platform, Mobile } \\
\text { App }\end{array}$ & $\begin{array}{l}\text { Automatic calibration system was } \\
\text { developed fothe } r \text { sensor system, } \\
\text { performed detailed power } \\
\text { consumption and computational } \\
\text { cost analysis }\end{array}$ \\
\hline 3. & $\begin{array}{l}\text { Sivasankari } \\
\text { et al. [49] }\end{array}$ & 2018 & $\begin{array}{l}\mathrm{RH} \text {, temperature, } \\
\mathrm{NO}_{2}, \mathrm{CO} \text { and } \\
\text { concentrations } \\
\text { of smoke }\end{array}$ & loT & UART & Raspberry Pi & $\begin{array}{l}\text { IP Address on } \\
\text { Web }\end{array}$ & $\begin{array}{l}\text { Data can be monitored from } \\
\text { anywhere by logging into } \\
\text { IP address. }\end{array}$ \\
\hline
\end{tabular}

controller unit, but the prime disadvantages of ZigBee modules are short communication range and low network stability with high maintenance cost. The highly efficient IoT systems bring new scope to this field. By using IoT architecture and the Raspberry Pi microcontroller, which has in-built Wi-Fi communication features ensure fast data transfer. Note that the most used Arduino boards do not offer direct network connectivity. Therefore, users need to use additional modules for internet accessibility. One commonly used Wi-Fi module for Arduino boards is ESP8266 chip, but it needs an external converter for 5-3 logic shifting since most Arduino microcontrollers use $5 \mathrm{~V}$ operating voltage. Moreover, it leads to additional cost and energy consumption. Furthermore, Raspberry Pi 3 has more processing power than Arduino Uno as the clock speed for the former is $1.2 \mathrm{GHz}$, whereas later works on $16 \mathrm{MHz}$.

Several methods for real-time IAQ monitoring are available in the literature. Furthermore, the presented methods provide practical solutions to improve occupational health and contribute to enhanced living environments considering numerous technical challenges. However, few improvements in the system performance are still required to ensure a reliable solution. By using an IAQ monitoring system, the manager can understand the IAQ behavior of the environment and plan interventions to avoid unhealthy situations. Therefore, the development of enhanced IAQ monitoring systems will address critical health challenges in today's world.

This section describes the weaknesses and strengths of the existing monitoring systems while describing the potential of available technologies and architectures. This in-depth review can guide new researchers to pick the most relevant topics for research in the future so that the quality of the living environment can be improved by inventing new methods and techniques.

\section{Conclusions}

In this review, the authors provide details about how various factors such as VOCs, $\mathrm{PM}_{10}, \mathrm{PM}_{2.5}, \mathrm{CO}, \mathrm{SO}_{2}$,

Table 4 Summary of IAQ monitoring systems based on other architectures

\begin{tabular}{|c|c|c|c|c|c|c|c|c|}
\hline Sr. No. & References & Year & $\begin{array}{l}\text { Parameters } \\
\text { considered }\end{array}$ & Architecture & $\begin{array}{l}\text { Communication } \\
\text { Interface }\end{array}$ & $\mathrm{MCU}$ & Data Access & Remarks \\
\hline 1. & Wu et al. [33] & 2017 & PM & C-Air platform & Not available & $\begin{array}{l}\text { Raspberry } \\
\text { Pi A+ }\end{array}$ & Mobile app & $\begin{array}{l}\text { Machine learning algorithm } \\
\text { was used for particle } \\
\text { detection and sizing }\end{array}$ \\
\hline 2. & $\begin{array}{l}\text { Zampolli } \\
\text { et al. [34] }\end{array}$ & 2004 & $\begin{array}{l}\mathrm{NO}_{x_{1}} \mathrm{CO}, \\
\text { VOCs and } \mathrm{RH}\end{array}$ & $\begin{array}{l}\text { eNose architecture } \\
\text { based solid-state } \\
\text { sensor array }\end{array}$ & $\begin{array}{l}\text { Custom-made } \\
\text { electronic } \\
\text { interface }\end{array}$ & ST52T301P & $\begin{array}{l}\text { Simulation } \\
\text { environment }\end{array}$ & $\begin{array}{l}\text { Fuzzy pattern recognition } \\
\text { algorithm was used }\end{array}$ \\
\hline 3. & Pillai et al. [37] & 2010 & $\begin{array}{l}\text { VOCs, CO, } \\
\text { hydrogen }\end{array}$ & $\begin{array}{l}\text { C-N based sensor } \\
\text { network }\end{array}$ & CAN & AT89C51CC03 & $\begin{array}{l}\text { LED } \\
\text { DisplaThe e }\end{array}$ & $\begin{array}{l}\text { Experiment was performed } \\
\text { on breadboards in a lab } \\
\text { environment }\end{array}$ \\
\hline 4. & $\begin{array}{l}\text { Cheng } \\
\text { et al. [39] }\end{array}$ & 2014 & $\mathrm{PM}_{2.5}$ levels & $\begin{array}{l}\text { Cloud-based } \\
\text { engine }\end{array}$ & $\begin{array}{l}\text { Bluetooth 0.4, } \\
3 \mathrm{G} \text { mobile data } \\
\text { connection and } \\
\text { Wi-Fi }\end{array}$ & Raspberry Pi & $\begin{array}{l}\text { Mobile } \\
\text { Apps, } \\
\text { WeThe p }\end{array}$ & $\begin{array}{l}\text { Prediction model was } \\
\text { designed using Artificial } \\
\text { Neural Network }\end{array}$ \\
\hline 5. & $\begin{array}{l}\text { Moreno-Rangel } \\
\text { et al. [47] }\end{array}$ & 2018 & $\begin{array}{l}\text { Fine } \mathrm{PM}_{2.5} \\
\mathrm{CO}_{2}, \mathrm{VOCs}, \\
\mathrm{RH} \text { and } \\
\text { temperature }\end{array}$ & $\begin{array}{l}\text { Foobot } \\
\text { FBT0002100 }\end{array}$ & Wi-Fi & Not available & $\begin{array}{l}\text { Cloud } \\
\text { System, } \\
\text { Tablet }\end{array}$ & - \\
\hline
\end{tabular}


$\mathrm{NO}, \mathrm{O}_{3}$, temperature, and $\mathrm{RH}$ affect IAQ. Furthermore, authors have highlighted the technical aspects of the studies performed by early researchers in this field. Trends reveal that most of the researchers till now have worked upon WSN and IoT architectures to study associated factors with IAQ and provide mobile computing software for data consulting.

Instead of working within a controlled laboratory environment or on simulation systems, researchers need to implement real-time IAQ monitoring systems in real scenarios. The development of prediction systems is another primary concern for future studies because it is easier to control the adverse impact of indoor air pollutants when we are aware of future happenings. Deep learning models such as LSTM and GRU can be utilized to design the prediction systems, and the instant alerts about variation in indoor pollutant levels above the threshold limit must be sent via SMS or email to the smartphones. Note that, LSTM is the enhanced strategy to traditional Recurrent Neural Network, whereas GRU is the further extension to LSTM with forget and update gates. These models work with parameterized functions that have a direct impact on ideal parameters of the data; hence lead to better prediction. Mobile app-based systems analysis is also an essential part of the design. This field has considerable scope for development, and future researchers need to work on in-depth design solutions by combining IoT and deep learning models to come up with cost-effective, accurate, and reliable IAQ management systems. However, the research should not be limited to the industrial environment and cities. Only slightly suitable systems must be designed for the village areas where people suffer more due to their excessive exposure to solid fuels. The development of such systems can lead to an incredible contribution to the medical health department as well.

The main areas of work for future researchers can be summarized as:

- Developing an IAQ monitoring system that can work efficiently in real-time conditions, instead of simulated or laboratory-based environments.

- Consider specific requirements of rural areas and design a cost-effective IAQ monitoring system to provide a safe solution for enhanced living environments.

- Work on IAQ prediction systems so that appropriate preventive measures can be followed on time.

- Designing a power-efficient and robust system for severe monitoring conditions in the urban as well as rural areas.

- Developing more efficient systems that can generate instant alerts to the users via email and SMS whenever IAP crosses certain threshold levels.
- Develop mobile app-based monitoring systems that can be operated by non-tech savvy people as well.

- Developing quick alert systems with possible preventive measures like switch on/off air conditioner, open/close windows, and check gas leakage to guide people towards healthy solutions with a variety of specific pollutants in the living environment.

In conclusion, the monitoring solutions/architectures proposed to address the IAQ should incorporate artificial intelligence to predict unhealthy situations for the enhanced living environment and occupational health.

\section{Acknowledgments}

The authors wish to thank the National Institute of Technical Teachers' Training and Research, Chandigarh, India, and Universidade da Beira Interior, Covilhã, Portugal, to provide the valuable resources to carry out this study.

\section{Authors' contributions}

All the authors have contributed to the structure, content, and writing of the paper. All authors read and approved the final manuscript.

Funding

The authors confirm that no funding was received to carry out this study.

Availability of data and materials

No such sources of data or materials are used for this study.

\section{Competing interests}

The authors declare that they have no competing interests.

\section{Author details}

${ }^{1}$ National Institute of Technical Teachers' Training \& Research, Chandigarh 160019, India. ${ }^{2}$ Institute of Telecommunications, University of Beira Interior, 6201-001 Covilha, Portugal.

Received: 3 September 2019 Accepted: 9 January 2020

Published online: 29 January 2020

References

1. Cincinelli A, Martellini T. Indoor air quality and health. Int J Environ Res Pu. 2017; $14: 1286$.

2. Arungu-Olende S. Rural energy. Nat Resour Forum. 1984;8:117-26.

3. de Koning HW, Smith KR, Last JM. Biomass fuel combustion and health. B World Health Organ. 1985;63:11-26.

4. Smith KR, Samet JM, Romieu I, Bruce N. Indoor air pollution in developing countries and acute lower respiratory infections in children. Thorax. 2000;55: 518-32.

5. Bruce N, Perez-Padilla R, Albalak R. Indoor air pollution in developing countries: a major environmental and public health challenge. B World Health Organ. 2000;78:1078-92.

6. Ezzati M, Kammen DM. Quantifying the effects of exposure to indoor air pollution from biomass combustion on acute respiratory infections in developing countries. Environ Health Perspect. 2001;109:481-8.

7. IEA. World Energy Outlook 2017. Paris: International Energy Agency; 2017.

8. Smith KR, Apte MG, Ma YQ, Wongsekiarttirat W, Kulkarni A. Air pollution and the energy ladder in Asian cities. Energy. 1994;19:587-600.

9. WHO. Fuel for life: household energy and health. Geneva: World Health Organization; 2006.

10. IEA, IRENA, UNSD, WB, WHO. Tracking SDG 7: the energy Progress report 2019. Washington: International Bank for Reconstruction and Development/ The World Bank; 2019.

11. Parajuli I, Lee H, Shrestha KR. Indoor air quality and ventilation assessment of rural mountainous households of Nepal. Int J Sustain Built Environ. 2016; 5:301-11. 
12. Dhakal S. Climate change and cities: the making of a climate friendly future. In: Droege P, editor. Urban energy transition. Amesterdan: Elsevier; 2008. p. 173-92

13. Lawrence A, Taneja A. An investigation of indoor air quality in rural residential houses in India - a case study. Indoor Built Environ. 2005;14:321-9.

14. Sehgal M, Rizwan SA, Krishnan A. Disease burden due to biomass cookingfuel-related household air pollution among women in India. Glob Health Action. 2014;7:25326.

15. Ritchie H, Roser M. Indoor air pollution. 2019. OurWorldlnData.org

16. Seppanen O, Fisk WJ. Association of ventilation system type with SBS symptoms in office workers. Indoor Air. 2002;12:98-112.

17. Graudenz GS, Oliveira CH, Tribess A, Mendes C, Latorre MRDO, Kalil J. Association of air-conditioning with respiratory symptoms in office workers in tropical climate. Indoor Air. 2005;15:62-6.

18. Wang Z, Bai Z, Yu H, Zhang J, Zhu T. Regulatory standards related to building energy conservation and indoor-air-quality during rapid urbanization in China. Energ Buildings. 2004;36:1299-308.

19. Bassani DG, Jha P, Dhingra N, Kumar R. Child mortality from solid-fuel use in India: a nationally-representative case-control study. BMC Public Health. 2010;10:491

20. Ramesh Bhat $Y$, Manjunath N, Sanjay D, Dhanya Y. Association of indoor air pollution with acute lower respiratory tract infections in children under 5 years of age. Paediatr Int Child H. 2012;32:132-5.

21. Priscilla J, Padmavathi R, Ghosh S, Paul P, Ramadoss S, Balakrishnan K, et al. Evaluation of mucociliary clearance among women using biomass and clean fuel in a periurban area of Chennai: a preliminary study. Lung India. 2011;28:30-3.

22. Wendling ZA, Emerson JW, Esty DC, Levy MA, de Sherbinin A, et al. 2018 environmental performance index. New Haven: Yale Center for Environmental Law \& Policy; 2018.

23. Thomas S, Morawska L. Size-selected particles in an urban atmosphere of Brisbane, Australia. Atmos Environ. 2002;36:4277-88.

24. Gramotnev G, Ristovski Z. Experimental investigation of ultra-fine particle size distribution near a busy road. Atmos Environ. 2004:38:1767-76.

25. Gorai AK, Tuluri F, Tchounwou PB. A GIS based approach for assessing the association between air pollution and asthma in New York state, USA. Int $J$ Env Res Pub He. 2014;11:4845-69.

26. Hesterberg TW, Bunn WB, McClellan RO, Hamade AK, Long CM, Valberg PA. Critical review of the human data on short-term nitrogen dioxide $\left(\mathrm{NO}_{2}\right)$ exposures: evidence for $\mathrm{NO}_{2} \mathrm{NO}$-effect levels. Crit Rev Toxicol. 2009;39:743-81.

27. Yu BF, Hu ZB, Liu M, Yang HL, Kong QX, Liu YH. Review of research on airconditioning systems and indoor air quality control for human health. Int Refrig. 2009;32:3-20.

28. Yang $X$, Chen Q, Zhang JS, An Y, Zeng J, Shaw CY. A mass transfer model for simulating VOC sorption on building materials. Atmos Environ. 2001;35: 1291-9.

29. Wainman T, Zhang JF, Weschler CJ, Lioy PJ. Ozone and limonene in indoor air: a source of submicron particle exposure. Environ Health Perspect. 2000; 108:1139-45.

30. Rohr AC, Weschler CJ, Koutrakis P, Spengler JD. Generation and quantification of ultrafine particles through terpene/ozone reaction in a chamber setting. Aerosol Sci Technol. 2003;37:65-78.

31. Nolte $H$, Backer $V$, Porsbjerg C. Environmental factors as a cause for the increase in allergic disease. Ann Allerg Asthma Im. 2001;87:7-11.

32. Alhmiedat T, Samara G. A low cost ZigBee sensor network architecture for indoor air quality monitoring. Intl J Comp Sci Inf Secur. 2017;15:140-4.

33. Wu YC, Shiledar A, Li YC, Wong J, Feng S, Chen X, et al. Air quality monitoring using mobile microscopy and machine learning. Light Sci Appl. 2017;6:e17046.

34. Zampolli S, Elmi I, Ahmed F, Passini M, Cardinali GC, Nicoletti S, et al. An electronic nose based on solid state sensor arrays for low-cost indoor air quality monitoring applications. Sensor Actuat B-Chem. 2004;101:39-46.

35. Kim JY, Chu CH, Shin SM. ISSAQ: an integrated sensing systems for real-time indoor air quality monitoring. IEEE Sensors J. 2014;14:4230-44.

36. Yu TC, Lin CC. An intelligent wireless sensing and control system to improve indoor air quality: monitoring, prediction, and preaction. Int $\rfloor$ Distrib Sens N. 2015;2015:140978.

37. Pillai MA, Veerasingam S, Yashwanth SD. Implementation of sensor network for indoor air quality monitoring using CAN interface. In: 2010 International Conference on Advances in Computer Engineering. Bangalore. 2010:20-1.
38. Abraham S, Li X. A cost-effective wireless sensor network system for indoor air quality monitoring applications. Procedia Comput Sci. 2014;34:165-71.

39. Cheng Y, Li X, Li Z, Jiang S, Li Y, Jia J, et al. AirCloud: a cloud-based airquality monitoring system for everyone. In: 12th ACM Conference on Embedded Network Sensor Systems. Memphis; 2014. p. 3-5.

40. Kang J, Hwang Kl. A comprehensive real-time indoor air-quality level indicator. Sustainability-Basel. 2016;8:881.

41. Bhattacharya S, Sridevi S, Pitchiah R. Indoor air quality monitoring using wireless sensor network. In: 2012 Sixth International Conference on Sensing Technology. Kolkata; 2012. p. 18-21.

42. Ahn J, Shin D, Kim K, Yang J. Indoor air quality analysis using deep learning with sensor data. Sensors Basel. 2017;17:2476.

43. Pitarma R, Marques $G$, Caetano F. Monitoring indoor air quality to improve occupational health. In: Rocha A, Correia A, Adeli H, Reis L, Mendonca Teixeira $M$, editors. New advances in information systems and technologies. Advances in intelligent systems and computing. Cham: Springer; 2016. p. 13-21.

44. Benammar M, Abdaoui A, Ahmad SHM, Touati F, Kadri A. A modular IOT platform for real-time indoor air quality monitoring. Sensors Basel. 2018;18:581.

45. Saad SM, Mohd Saad AR, Kamarudin AMY, Zakaria A, Shakaff AYM. Indoor air quality monitoring system using wireless sensor network (WSN) with web interface. In: 2013 International Conference on Electrical, Electronics and System Engineering. Kuala Lumpur. 2013:4-5.

46. Tiele A, Esfahani S, Covington J. Design and development of a low-cost, portable monitoring device for indoor environment quality. J Sensors. 2018; 2018:5353816.

47. Moreno-Rangel A, Sharpe T, Musau F, McGill G. Field evaluation of a lowcost indoor air quality monitor to quantify exposure to pollutants in residential environments. J Sens Sens Syst. 2018;7:373-88.

48. Idrees Z, Zou Z, Zheng LR. Edge computing based loT architecture for low cost air pollution monitoring systems: a comprehensive system analysis, design considerations \& development. Sensors Basel. 2018;18:3021.

49. Sivasankari B, Prabha CA, Dharini S, Haripriya R. IoT based indoor air pollution monitoring using raspberry pi. Int J Innov Eng Tech. 2017;9:16-21.

50. Arroyo P, Herrero JL, Suarez JI, Lozano J. Wireless sensor network combined with cloud computing for air quality monitoring. Sensors Basel. 2019;19:691.

\section{Publisher's Note}

Springer Nature remains neutral with regard to jurisdictional claims in published maps and institutional affiliations.

Ready to submit your research? Choose BMC and benefit from

- fast, convenient online submission

- thorough peer review by experienced researchers in your field

- rapid publication on acceptance

- support for research data, including large and complex data types

- gold Open Access which fosters wider collaboration and increased citations

- maximum visibility for your research: over $100 \mathrm{M}$ website views per year

At BMC, research is always in progress.

Learn more biomedcentral.com/submissions 